Ewelina Wnuk* and Yuma Ito

\title{
The heart's downward path to happiness: cross-cultural diversity in spatial metaphors of affect
}

https://doi.org/10.1515/cog-2020-0068

Received June 26, 2020; accepted January 23, 2021;

published online March 3, 2021

Abstract: Spatial metaphors of affect display remarkable consistencies across languages in mapping sensorimotor experiences onto emotional states, reflecting a great degree of similarity in how our bodies register affect. At the same time, however, affect is complex and there is more than a single possible mapping from vertical spatial concepts to affective states. Here we consider a previously unreported case of spatial metaphors mapping Down onto desirable, and up undesirable emotional experiences in Mlabri, an Austroasiatic language of Thailand and Laos, making a novel contribution to the study of metaphor and Cognitive Linguistics. Using first-hand corpus and elicitation data, we examine the metaphorical expressions: klol jur 'heart going down' and klol khun 'heart going up'/klol ksbs jur 'heart not going down'. Though reflecting a metaphorical mapping opposite to the commonly reported HAPPY IS UP metaphor, which is said to link to universal bodily correlates of emotion, the Mlabri metaphors are far from idiosyncratic. Rather, they are grounded in the bodily experience of positive low-arousal states, and in that reflect an emic view of ideal affect centered on contentment and tranquility. This underscores the complexity of bodily experience of affect, demonstrating that cultures draw on the available sensorimotor correlates of emotion in distinct ways.

Keywords: emotion; happiness; ideal affect; metaphor; Mlabri

\section{Introduction}

Talking about emotion in spatial terms feels natural. Phrases such as You're in high spirits, I'm feeling up or He's really low these days and My heart sank are common everyday expressions with seemingly intuitive meanings, whereby spatial

*Corresponding author: Ewelina Wnuk, Department of Anthropology, University College London, London, WC1H 0BW, UK, E-mail: e.wnuk@ucl.ac.uk

Yuma Ito, Research Institute for Languages and Cultures of Asia and Africa, Tokyo University of Foreign Studies, Fuchu, Tokyo, Japan, E-mail: yuma.i.86@gmail.com 
orientations are mapped onto emotional states (Crawford 2009; Kövecses 1991, 2008; Lakoff and Johnson 1980, 1999; Tolaas 1991). The underlying metaphors HAPPY IS UP and SAD IS DOWN are manifested with similar metaphorical expressions across several unrelated languages, e.g., English, Hungarian, and Mandarin (Lakoff and Johnson 1980; Yu 1995), and have been proposed to be universal or near-universal (Kövecses 2008). They are also considered to be primary metaphors, i.e., metaphors that arise directly from universal aspects of human experience and are "natural or even inevitable consequences of recurring associations in daily life” (Grady 1997, 2007: 193-194). In the case of happiness and sadness, these universal experiences are said to be associated with high and low positions in space co-occurring with happy and sad feelings: "Drooping posture typically goes along with sadness and depression, erect posture with a positive emotional state" (Lakoff and Johnson 1980: 15).

However, while some accounts stress the universality and inevitability of primary metaphors, universally shared associations do not necessarily have to lead to universal metaphors. Different aspects of bodily experience may be used selectively to result in metaphorical variation, reflecting 'differential experiential foci' of particular communities (Kövecses 2005). For example, different bodily and cultural motivations have been shown to shape different metaphorical conceptualizations of anger across languages (e.g., as liquid/gas in a container, fire, natural force, etc.) (Kövecses 1986, 2000, 2005). The same could be true of general affect, especially considering that affective states are complex, consisting minimally of two basic dimensions: valence (good vs. bad) and arousal (active vs. inactive) (Barrett 2006; Russell 1980; Russell and Barrett 1999). In addition, people's ideas about what states are most desirable for their well-being (i.e., the ideal affect) are not uniform across cultures, so we could well expect cross-linguistic variation in metaphorical language expressing them. Whereas most people generally prefer positive states, people in Western cultures (e.g., the US) tend to display a preference for high-arousal positive (HAP) states such as elation, whereas people in East Asian cultures (e.g., Japan) tend to prefer low-arousal positive (LAP) states such as contentment (Kitayama et al. 2000; Tsai 2007; Tsai et al. 2006). Still, despite cross-cultural variation in arousal preference, many investigations of spatial metaphors of affect tend to concentrate on valence alone, indirectly implying a fairly uniform picture of ideal affect across cultures (Casasanto and Bottini 2014; Crawford 2009; Crawford et al. 2006; Meier and Robinson 2004; Tolaas 1991; Yu 1995).

This approach overlooks the role of arousal and may suggest metaphors of affect can be reduced to valence. Yet, arousal too is relevant, as it manifests in conceptual metonymies often tied to particular metaphors (Kövecses 1991). Even a cursory examination of the metaphorical semantics of expressions such as be in high spirits shows arousal as an integral aspect of their meaning. The Oxford 
English Dictionary, for instance, defines high as "emotionally uplifted, in a good mood", as well as "elated, lively, uproarious", ${ }^{1}$ and similar arousal-related semantic components are present in other spatial metaphorical expressions of affect. The idea of happiness contained in these English expressions is in line with the ideal affect typically articulated in the US and other Western cultures, where it is equated with HAP states, as illustrated in the following definition of an ideal state representative of US respondents: "I just want to be happy. Normally for me that means I would be doing something exciting. I just want to be entertained ... I just like excitement" (Tsai 2007: 244; cf. also Lu and Gilmour 2004; Tsai et al. 2006; Uchida and Kitayama 2009).

The preference for HAP states among Westerners is echoed also in the metaphor literature in the discussions of spatial metaphors of affect: "a happy person is 'high on life"' (Casasanto and Bottini 2014: 140), "we also witness the physical expression of HAPPY IS UP when a football player, after scoring a goal, throws up his arms and jumps for joy” (Radden 2003: 414-415), “when we are joyful, we tend to be up, moving around, be active, jump up and down" (Kövecses 2008: 55). These examples are strikingly non-neutral when it comes to arousal. The rich evidence for valence-to-verticality association notwithstanding, the question remains whether arousal too is associated with verticality, and whether the spatial mappings in spatial metaphors of affect are impacted by this association.

In this article, we address this question and look at the role of valence and arousal in how happiness is conceptualized in spatial terms. Given the complex nonunidimensional nature of affect, we employ the terms 'desirable' and 'undesirable' when talking about affective states generally, and use the terms 'positive' and 'negative' when referring to the valence dimension specifically. Following a brief introduction to Mlabri, a Khmuic (Austroasiatic) language of Northern Thailand and Laos (Section 2), we present linguistic evidence on heart-based emotion metaphors in Mlabri (Section 3) and focus on the metaphorical expressions klol jur 'heart going down', mapping onto desirable, and klol khun 'heart going up'/klol kJbs jur 'heart not going down', undesirable emotional states. In line with the Mlabri perceptions of happiness and well-being, but contrary to English speakers' perceptions (Tsai 2007), these phrases reflect a view of ideal affect prototypically associated with low-arousal positive states such as contentment and tranquility. We examine closely these metaphorical expressions by looking at their use in discourse, supplementing the analysis with observations from co-speech gesture (Section 4), suggesting Mlabri speakers represent the relevant emotional states on the vertical axis, as expected based on the linguistic metaphors. We show that, although exhibiting a mapping

1 "high, adj. and n.2". OED Online. June 2020. Oxford University Press. https://www.oed.com/ view/Entry/86850?rskey=HWC6mC\&result=1 (accessed June 3, 2020). 
opposite to the seemingly ubiquitous HAPPY IS UP, these metaphors are not idiosyncratic or disembodied. Rather, they are grounded in the experience of affect, with physiological manifestations of arousal serving as the metaphoric vehicle for the affective concept. We probe the meaning of these expressions further through stimulus-based semi-structured interviews focused on antecedent Objects (cf. Russell 2003) of klol jur and klol khun/klol kabs jur (Section 5). We end with an ethnography-based exploration shedding light onto the Mlabri emic views of ideal affect (Section 6) followed by a Discussion (Section 7) and Conclusion (Section 8), thus highlighting the sociocultural background in which these metaphors arose and underscoring the complex socially constructed nature of emotions.

\section{Mlabri and its speakers}

Mlabri is a language spoken by about 400 people in Northern Thailand and Laos. The ethnonym mla? bri? literally means 'people of the forest'. Until recently, Mlabri people were forest-dwelling hunter-gatherers with an egalitarian social organization and low division of labor (Pookajorn 1992: 95). In the 80s and 90s, forced by progressing deforestation and growing pressure from the Thai government, the Mlabri began to settle down in villages across the Nan and Phrae provinces of Northern Thailand (Nimonjiya 2013), supporting themselves primarily by waged labor on rice and corn fields of the neighboring groups, and to a lesser degree farming of their own land, small-scale husbandry, and occasional gathering and hunting practices.

The Mlabri language belongs to the Khmuic branch of the Austroasiatic language family. It is an isolating language with a basic SVO constituent order, relatively rich derivational morphology, and ample lexical borrowing from Thai. Unlike its close relative - Kammu - Mlabri did not develop lexical tone and resisted the wider areal trend of contact-induced tonogenesis (Bätscher 2015; Rischel 1995). The current study focuses on the largest of the three recognized Mlabri dialects, referred to as $\alpha$-Mlabri in the literature, as spoken in Baan Huai Yuak of the Nan province in Northern Thailand - presently the largest Mlabri settlement. All Mlabri examples are rendered using IPA-based orthography (cf. Bätscher 2015).

\section{Heart-based emotion metaphor in Mlabri}

In Mlabri the center of emotional and thought processes is located in the heart, expressed with the term klol or its reduplicated variant klklol. As in many other cultures in Asia and across the world (e.g., Boster 2005; Lutz 1985; Wikan 1992; Yu 
2007), and in line with the Buddhist concept of 'heart-mind' (Thai jai, Pali/Sanskrit citta) dominant in Thailand, the Mlabri do not make a sharp distinction between emotions and thoughts, attributing similar nature to all inner processes. There is thus no lexical distinction between emotions and thoughts in Mlabri, both of which are expressed with the borrowed verb gut 'to feel, to think' (Thai khit) and a somewhat less integrated loan rusuk 'to feel, to think' (Thai rúusèuk). When used in relation to feeling, these verbs are also ambiguous with respect to whether they relate to purely physical sensations or inner states, and the word klol 'heart' can in fact be used to mark the inner state reading explicitly, e.g., gut di klol '(I) feel an emotion/have a thought, lit. feel in my heart' (feel POSS heart).

The word klol 'heart' in Mlabri is also a source of conventionalized metaphorical expressions of emotion, indexing the central role of the heart in Mlabri perceptions of affect. The Mlabri view of emotions as coded in language is thus predominantly cardiocentric, similar to many other languages in Mainland Southeast Asia (Matisoff 1986) and worldwide, in which the heart is conceptualized as the seat of emotions and is the primary bodily metaphoric vehicle for emotion concepts (Sharifian et al. 2008).

The linguistic pattern of heart-based metaphors in Mlabri relies on klol compounds, with klol either in the initial, e.g., klol pluy 'be angry (hot heart)', or final position, e.g., Pon klol 'be sad (soft heart)'. This pattern is similar to the pattern underlying heart-based (jai 'heart') expressions in Thai (Moore 2013), though it is far less prolific and extends into fewer domains. The conventionalized Mlabri klol expressions number less than a dozen and - unlike jai expressions in Thai - seem to be restricted to canonical emotional states, with no instances of cognitive meanings such as 'understand' or 'decide' presently recorded.

While there are clear similarities and clear differences between Mlabri and Thai, it is difficult to say whether the heart-based metaphorical pattern itself is indigenous or borrowed. Some specific instances of $k l o l$ metaphorical expressions are modelled on Thai as either word-for-word calques, e.g., klol tck 'be calm, composed (lit. cool heart)' (Thai jai yen), or hybrid Thai-Mlabri expressions, ?on klol 'be sad' (Thai jon jai), sometimes with related, but not fully equivalent, meanings. There are also instances of full borrowings, e.g., di jai 'be happy' (Thai dii jai) with minor phonological adaptations ( $d$ instead of $d$ ). Finally, there are also klol expressions in Mlabri that do not have Thai counterparts, suggesting a Mlabrispecific conceptualization of affective experience. A case in point here are the expressions klol jur 'be happy, content, calm (heart going down)' and klol khun 'be upset, distressed, unhappy (heart going up)' (Thai khêun 'to go up'), with no corresponding equivalents *jai long or *jai khêu in Thai.

Other Mlabri dialects (Rischel 1995: 52) and closely related Khmuic languages, e.g., Kammu (Ahlner 2010), make use of similar heart-based metaphors - suggesting 
a degree of historical depth for such expressions within the branch. However, given the long-term contact of Khmuic with Thai and Lao, it is difficult to determine with certainty whether the klol-based metaphors originated within the branch or if they were acquired through contact. Irrespective of their origin, however, they are a significant part of the Mlabri emotion lexicon, especially flexible and dynamic, and seemingly gaining importance in recent decades. The klol compounding pattern allows easy creation of new emotion terms, with Thai jai compounds being an accessible source to model. The pattern has been fairly productive in recent years as new items, unrecorded in previous lexica just about 30-40 years ago (Egerod 1982; Egerod and Rischel 1987), are now in common use, e.g., ?on klol 'be sad', and several others that seem to exist in individual speakers' idiolects might eventually become conventionalized.

\section{Mlabri spatial metaphors of affect in lexicon and gesture}

What role does vertical space play in heart-based conceptualizations of affect? Two Mlabri expressions are of relevance to this question: klol jur, literally meaning 'heart is going down' (heart go.down) and klol khun meaning 'heart is going up' (heart go.up). Both use the body and vertical space as source domains and reflect the grounding of the abstract affective concepts in the physical world. Klol jur is conventionally used to refer to a range of desirable emotional states such as happiness, ease, and contentment, and is translated by Mlabri speakers into Thai as dii jai 'be happy (lit. good heart)'. Klol khun 'heart is going up', on the other hand, relates to undesirable feelings of emotional agitation and distress, and is translated into Thai as jai mâi dii 'lit. not good heart', a general term used for a range of emotions, including feeling angry, upset, frightened, dejected, and worried.

Mlabri speakers also routinely employ a negated term, i.e., klol kobo jur 'heart is not going down' (heart NEG go.down) - to refer to undesirable states, much like it is done in English (e.g., unhappy), Thai (e.g., mâi dii), and many other languages (e.g., Polish - nieszczęśliwy, Italian - infelice, Dutch - ongelukkig, etc.). Klol kobs jur is best described as indicating emotional agitation, and it can be linked to a range of more specific states (e.g., being upset, angry, distressed, frightened, worried, etc.). Though largely similar in meaning, klol khun and klol kobs jur differ in their aspectual semantics. Klol khun has an inchoative meaning, profiling the inception of a state, while klol kJbJ jur places the focus on the state itself. In most ordinary contexts, they are interchangeable. Yet, frequency-wise, klol kJbo jur is more common. 
Examples (1)-(3) below are spontaneous instances of klol kobs jur attested in the corpus recorded by the second author over several years of fieldwork. While the specific emotions in each case are not the same, they are all instances of emotional agitation and uneasiness. The examples indicate the term can be applied broadly and can stand for a single emotional episode in reaction to a specific antecedent event as well as a more general emotional state experienced over a longer period. In (1), a Mlabri woman complains about her Hmong employer not having kept their promise, expressing her anger and irritation at the situation. In (2), a man speculates why another Mlabri man moved to another village, suggesting his decision was likely caused by lack of happiness, whereas in (3) a Mlabri elder describes the general circumstances of life in Baan Huai Yuak referring to both happy and unhappy ones. Tellingly, in this last instance klol kJbs jur is juxtaposed with the expression klol di 'good heart', essentially a near-synonym of klol jur.

$\begin{array}{llllllll}\text { kwır } & \text { thuklunk } & P a-d \varepsilon, & j r m u k & k w \wedge r, & y a ? & \text { klol } & \text { kobo } \\ \text { outsider } & \text { lie } & \text { PF-true } & \text { dislike } & \text { outsider } & \text { auntie } & \text { heart } & \text { NEG } \\ \text { jur } & \text { Pa-d } d \varepsilon & & & & & & \\ \text { descend } & \text { PF-true } & & & & & & \end{array}$

'The outsider lied. I don't like them, I am upset indeed (my heart isn't going down)!'

(2)

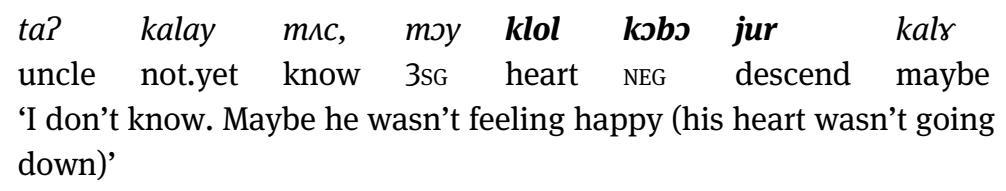

(3)
$\begin{array}{lllllllll}\text { klol } & \text { di } & k \jmath & \text { pr?, } & \text { klol } & \text { kobs } & \text { jur } & \text { ko } & \text { pr? } \\ \text { heart } & \text { good } & \text { also } & \text { exist } & \text { heart } & \text { NEG } & \text { descend } & \text { also } & \text { exist }\end{array}$
'There are happy and unhappy ones (those in which one's heart isn't going down),

All three klol jur, klol kJbJ jur, and klol khun may be employed with a perfective marker $? a$, marking a resultative reading, e.g., klol $3 a$ jur 'heart has gone down' (heart PF go.down), or simply by itself with a more processual reading, i.e., klol jur 'heart is (going) down'. Thus, depending on the grammatical form, the conceptualization draws on different aspects of the space domain: motion through (cf. Zlatev et al. 2012), or location in, vertical space.

The specific space-to-affective-state mappings of Down onto the desirable and UP undesirable emotional states might at first appear counterintuitive (Crawford 2009; Lakoff and Johnson 1980). Considered from the standpoint of valence alone, these metaphorical mappings appear idiosyncratic or disembodied. Yet, their meanings are consistent with the arousal of the relevant affective states, i.e., the 
prototypical undesirable emotions mapped onto UP are high-arousal states, whereas the prototypical desirable emotions mapped onto Down are low-arousal states. The metaphoric vehicles, i.e., the actual expressions themselves too reveal a link with arousal as manifested by one's heart moving down or up in the chest.

Although expressed in terms evoking arousal, the expressions klol jur and klol $\mathrm{khun} / \mathrm{klol}$ kJbojur do not refer to the levels of arousal specifically, but rather affective states generally. They are best translated as 'happy, content, calm' and 'unhappy, emotionally agitated, distressed', as shown by Mlabri speakers' definitions and use in context. As affective terms, these expressions are part of the same contrast set as other emotion terminology and form paradigmatic relationships with them. Klol jur is often paraphrased with the term klol di 'be happy (lit. good heart)' and sometimes also klol tck 'be calm, composed (lit. cool heart)'. Klol kJbs jur and klol khun, on the other hand, are similar to and are sometimes used interchangeably with klol kobj di 'unhappy (lit. not good heart)' and jut 'be upset, angry, sad'. The two sets are contrastive and are treated as opposites, occurring in sentence frames such as the one in (3), suggesting they function as antonyms and near-antonyms. No additional metaphors for desirable states have been recorded in Mlabri. As for undesirable states, an additional softness metaphor exists for sadness: ?on klol 'be sad' (Thai j̀on jai), with no corresponding hardness metaphor.

The Mlabri do not only talk about desirable and undesirable affective states using spatial metaphors, but they also gesture accordingly. Our preliminary observations of co-speech gesture patterns show that - as predicted from the linguistic space-to-affect mappings - talking about the states covered by klol jur is accompanied by downward-directed gestures, whereas klol khun/klol kəbs jur-related states are accompanied by upward-directed gestures. The underlying conceptual structure thus gets manifested both verbally and bodily, suggesting metaphoricity at the linguistic and cognitive level of structure (Cienki and Müller 2008; McNeill 1992; Sweetser 2007).

Examples below come from a speaker who was asked to provide definitions of klol jur and klol khun. The speaker relied on paraphrases in Thai, mixing them with Mlabri. In both cases, he produced multiple gestures, some of which were co-timed with klol jur and klol khun, some of which occurred simultaneously with Thai translations or during a pause.

Example (4) shows the speaker juxtaposing the phrase jai dii 'good heart' in Thai with the Mlabri equivalent. He produces a similar gesture twice, moving his hand down while holding it in front of his chest, as visible in the image in Figure 1. The first gesture is co-timed with the Thai intonational phrase jai dii khráp 'the heart is good' and the second one with jur 'going down'. The duration of the stroke, i.e., "the main motion phase of a gesture" (Sweetser 2007: 203), is indicated by the lines under the utterance. The first instance involves a complex stroke (cf. Kendon 2004), i.e., a set of quick repeated downward movements, while the second one is a single downward movement. 


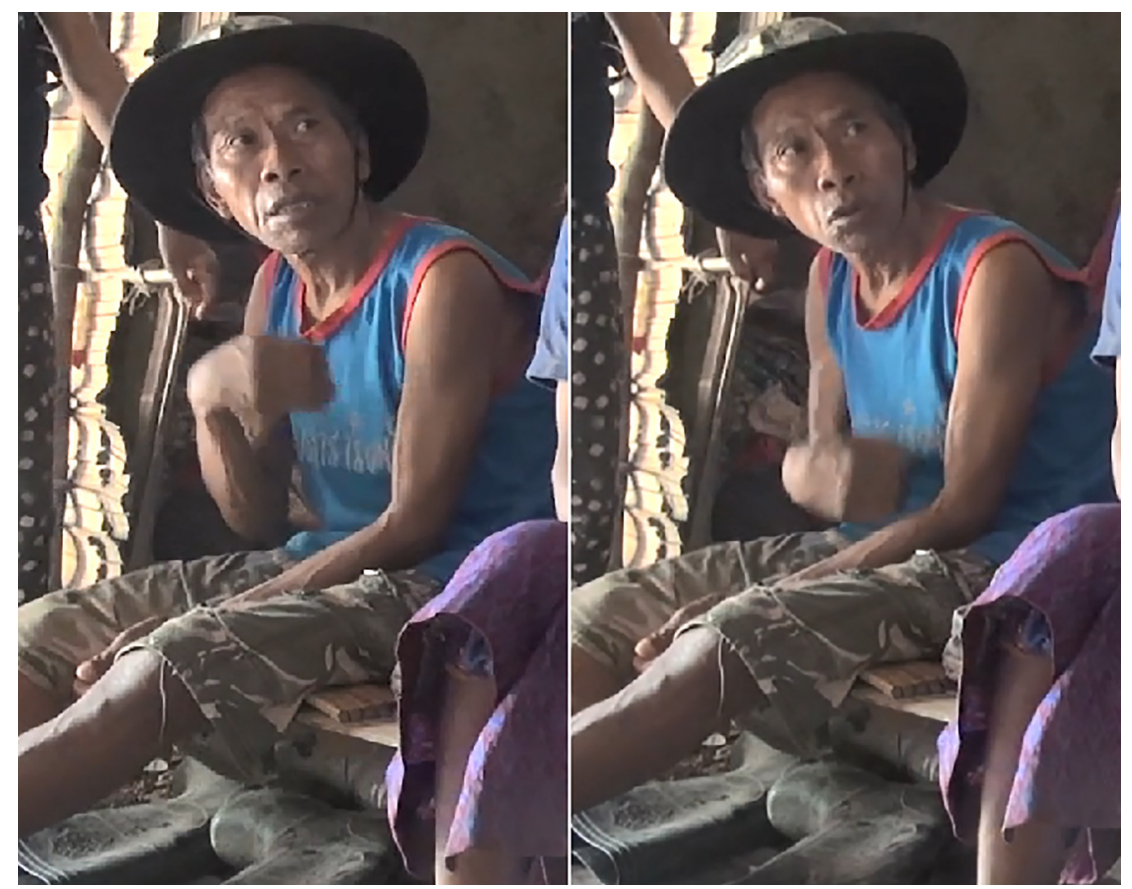

Figure 1: Screenshots of the second gesture in Example (1). The speaker moves his hand down in front of his chest while pronouncing the word jur.

(4) Jai dii khráp. Smbep thot. Mla? tın ?a jai jur Heart good $\mathrm{P}$ language Thai Mlabri say comp heart go.down 'The heart is 'good', in Thai. The Mlabri would say heart goes down.'

In (5) below, we see a similar pattern. This time, the speaker makes three similar upward-directed gestures when explaining the meaning of klol khun. Here, the stroke is first produced directly after the Thai equivalent jai mâi dii, with no overlap with speech, and subsequently in alignment with two instances of the verb khwn. In all cases, the stroke involves the speaker moving his hand upwards in front of his chest, as illustrated in Figure 2. As previously, the examples involve both simple and complex strokes. Note also that the utterance is accompanied by a slight upward head tilt, congruent with the manual gestures.

(5) Jai mâi dii. Jai khun. Mla? gut tın Pa klol... klol khun heart NEG good - heart go.up person feel say comp heart heart go.up 'Unhappy (lit. heart isn't good). The heart is going up. One feels the heart ... the heart is going up.' 


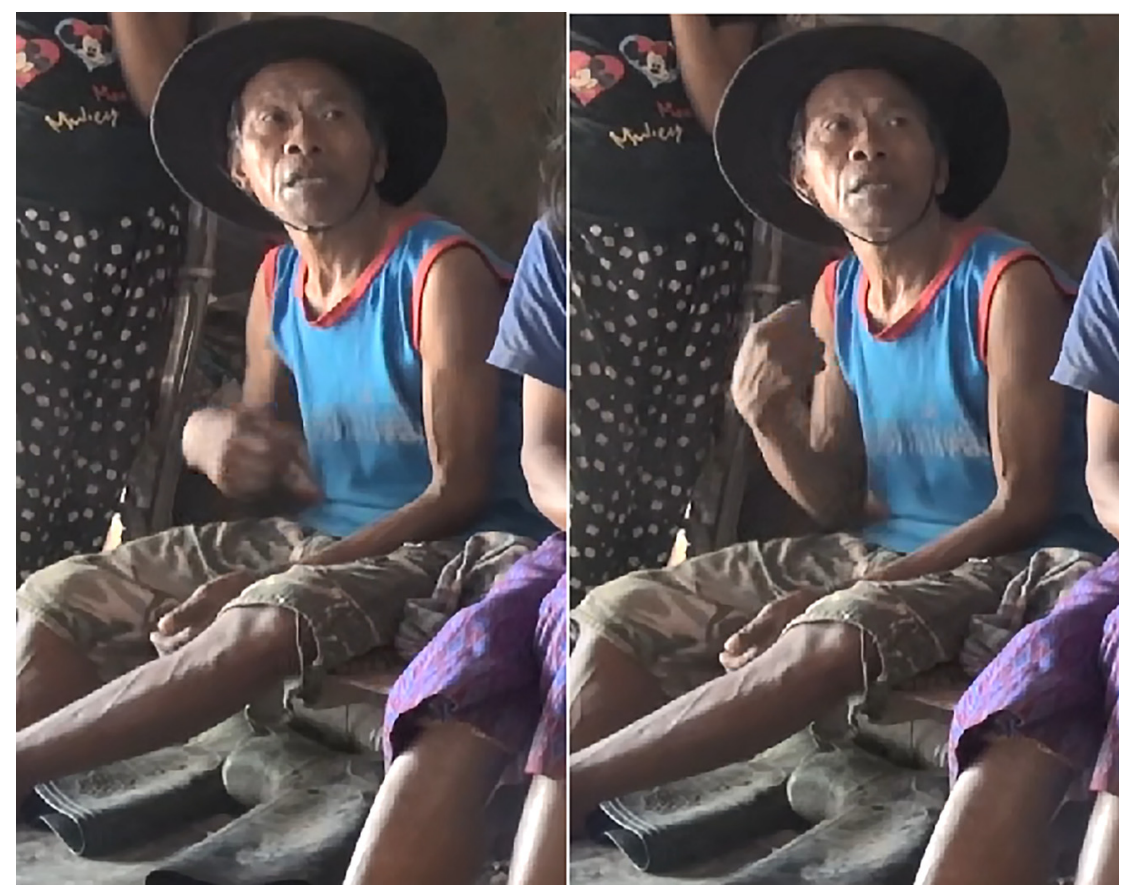

Figure 2: Screenshots of the second gesture in Example (2). The speaker moves his hand up in front of his chest and tilts his head back slightly while pronouncing the word khun.

The patterns exemplified here are in stark contrast to affect-related gesture patterns reported for other languages, e.g., German, where downward gestures are reported for sadness and depression (Müller 2008). The metaphorical contrast described is thus evident not only in the lexicon, but also at the nonverbal level, ultimately suggesting that the difference we are observing is not merely linguistic.

Summarizing, the basic meaning of klol jur and klol khun/klol kobs jur as expressed by Mlabri speakers is to feel happy and calm, and unhappy, respectively. These feelings are linked to the subjective physiological experiences of one's heart that evoke physiological reactions associated with low- and higharousal states. In the following, we explore what emotional Objects (capitalized following Russell 2003: 147, who defines Object as "the person, condition, thing, or event at which a mental state is directed") they could be directed at to further uncover the extensional range of affective states that fall under the scope of these expressions. 


\section{The semantic scope of klol jur and klol khun/ klol kobo jur}

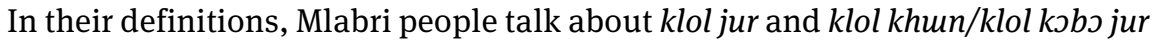
as two opposite kinds of affective states associated with happy and unhappy feelings. And while the metaphoric vehicles are evocative of arousal, both arousal and valence are important components of their semantics. What are then the combinations of arousal and valence that the expressions klol jur and klol khun/klol kobs jur are associated with? To find out, we carried out interviews with visual stimuli exploring the semantic scope of these expressions in greater depth.

\subsection{Interviews}

We asked nine Mlabri speakers to view 20 images from the Open Affective Standardized Image Set (OASIS) (Kurdi et al. 2017) and determine whether they made them feel klol jur and klol khwn and why. We selected images representing a wide variety of affective qualities (cf. Russell 2003) based on standardized ratings, i.e., high valence-high arousal (e.g., cliff diver), high valence-low arousal (e.g., grass), low valence-low arousal (e.g., woman in a bored pose), low valence-high arousal (e.g., forest on fire). The available ratings were based on American participants' judgments. We did not assume they overlapped with Mlabri people's evaluations, but used them as approximate indicators of valence and arousal to make sure the attributed affect would be varied across the set.

The investigation took the form of a semi-structured ethnographic interview, so as to allow the possibility of elaborated responses, retellings of personal stories, or other potentially insightful commentary. The interviewed speakers were given images printed out in color as prompts and were asked whether they made them feel klol jur and klol khwn and why that was the case. Speakers were not forced to choose between klol jur and klol khun and in some cases they provided other

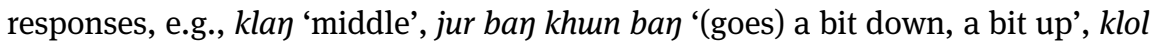
saw 'be sad (lit. sad heart, Thai saw "be sad")', or did not give any response. Since we were primarily interested in why different images were judged to arouse the feelings of klol jur and klol khun, for each response we also asked the participants to provide justifications for their responses, so as to see what emotional evaluations are associated with these two categories. The interviews were carried out in Mlabri. 
The responses could be summarized as follows. Ten of the 20 images $^{2}$ were deemed to evoke the feeling of klol jur in the majority of speakers (at least five out of the nine): dancing children, cat, puppy, yarn, rocks, grass, power lines, paper, lake, and thunderstorm. Five images were primarily associated with the feeling of klol khun/klol kobs jur: dog attack, forest fire, cliff diver, woman in a bored pose, and explosion, while the remaining five images did not have a clear predominant response: wall, miserable face, timber, dirt, and toilet. These choices mostly aligned with our predictions, but some aspects of this pattern were unexpected. For example, we expected the thunderstorm image to stir up the idea of danger and hence be associated with klol khun (as thunderstorms are greatly feared by the Mlabri, cf. Trier 2007). The speakers, however, judged it as evoking klol jur because they considered the scene captured in the image beautiful. Similarly, the power lines image, which we expected to evoke negative connotations, was deemed as klol jur by several speakers who appreciated the natural scenery in the background. Sometimes the same image was considered to evoke both $\mathrm{klol} \mathrm{jur} \mathrm{and} \mathrm{klol}$ khun/klol ksbs jur. For example, one speaker pointed out that the cliff and water in the cliff diver image were beautiful (and hence provoked klol jur), yet the idea of jumping into the water from a great height was frightening (and hence would make her feel klol ksbs jur). Given the possibility of such variable construals, it is difficult to make strong generalizations based on the initial responses alone. We therefore further examined the reasoning behind the appraisals (why is it klol jur/klol khun/klol kobs jur?) to shed more light onto to the logic underlying people's judgments. As this part of the interview required generating reasons that in some cases were not immediately accessible to the speakers, they found it more challenging and were sometimes unable to provide a justification (four of the nine speakers provided reasons for fewer than five responses). A selection of commonly provided reasons is given in Table 1, which lists them along with examples of the relevant images. Note that although speakers were instructed to give the initial response based on how the image made them feel, they focused on both their own relationship to the image (e.g., "I don't like looking at it") and aspects of the image itself (e.g., "she's thinking a lot").

The overall pattern emerging from the justifications suggests klol jur is associated with emotional Objects which are liked, pleasant to look at, and which evoke good feelings. These include feeling glad, happy, and joyful, witnessing beautiful natural scenery (grass, rocks, river) and other aesthetically pleasing objects (colorful yarn). Klol kJbo jur and klol khun on the other hand, are associated with

2 The names of the selected images in OASIS are: Dancing 7, Grass 3, Cat 5, Yarn 4, Rocks 6, Paper 2, Power lines 1, Lake 2, Dog 6, Bored pose 3, Thunderstorm 9, Wall 4, Miserable face 2, Timber 3, Dirt 5, Explosion 2, Toilet 4, Cliff diver 3, Fire 11, and Dog attack 3. 
Table 1: Selected justifications for klol jur and klol khun/klol kəbə jur.

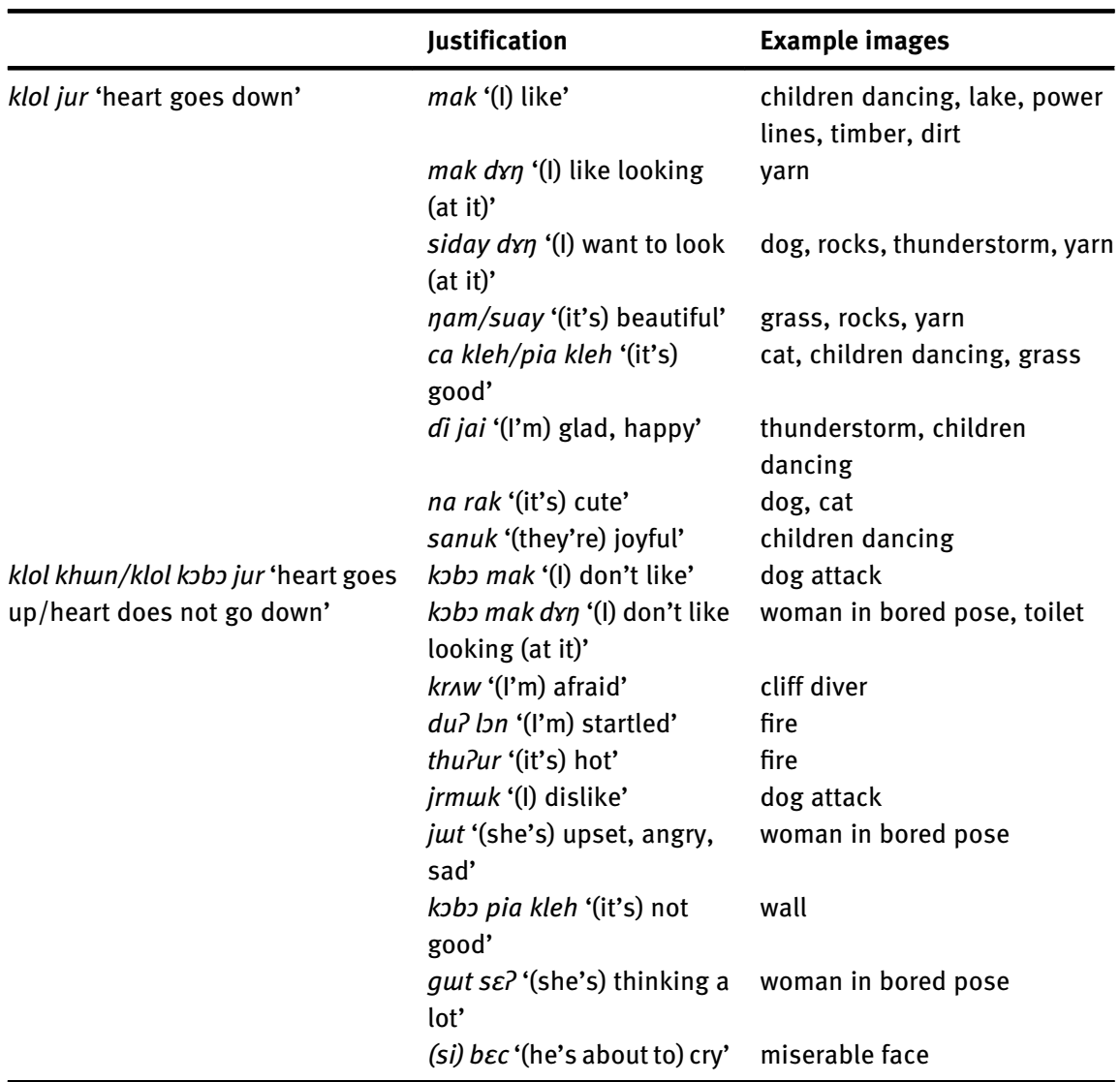

emotional Objects which are disliked, unpleasant to look at, and which evoke bad feelings. These range from dislike, fear, fright, anger, sadness, to 'thinking a lot' (a cross-culturally common idiom of distress linked to persistent worrying; cf. Kaiser et al. 2015).

Excitement (high valence-high arousal) and boredom (low valence-low arousal), which do not seem to fit neatly with either of the two categories, were targeted by the images of a woman in a bored pose and cliff diver, but it wasn't possible to resolve whether these emotions could be subsumed under klol jur or klol $k J b J j u r / k l o l ~ k h u n$. The woman in a bored pose image was most often interpreted as a person in distress (gut se? 'thinking a lot', ?on klol 'be sad', jut 'be upset, sad, angry') rather than simply someone bored, and was classified as klol khun/klol kJbo jur in line with this interpretation. The cliff diver image, on the other hand, elicited mixed 
responses, reflecting the ambiguity that resulted from the variety of emotions evoked by different construals of this image. This could mean that excitement of the kind depicted in the photo might escape clear-cut categorization in Mlabri, but given the cultural relativity of what activities are considered pleasurable (cf. Tsai 2007), further investigation is necessary to probe a wider variety of situations.

Thus, consistent with the definitions given by Mlabri speakers, all states entailed by the term klol jur are necessarily positive and all those entailed by klol khun/klol ksbo jur negative. They are also mostly consistent with the association of low arousal with klol jur and high arousal with klol khun/klol kobs jur, although there seems to be some flexibility in this respect since Objects of both categories seem to cover a range of arousal levels. Further investigation, with arousal targeted directly in explicit ratings, could help determine the range of flexibility with more precision.

The data from interviews together with insights from discourse and gesture shed light on the semantics of klol jur and klol khun/klol kobs jur and help elucidate the bodily basis of the underlying metaphors. To deepen our understanding of these metaphorical patterns further, we now turn to the broader sociocultural context in which they arose and examine Mlabri people's emic notions of ideal affect.

\section{Sociocultural context of ideal affect among the Mlabri}

While being grounded in universal bodily experiences, metaphors of affect are also inevitably motivated by sociocultural factors since ideal affect (i.e., people's desired affective states) is not merely biological, but is shaped by sociocultural forces (Geertz 1975; Lutz 1988; Rosaldo 1980; Wierzbicka 1999). Metaphors of affect, therefore, are both embodied and cultural at the same time (cf. Winter and Matlock 2017). What is then the sociocultural context of the spatial heart-based metaphors in Mlabri?

Previous cross-cultural work showed ideal affect is related to how individuals construe their self-image in relation to others, and how this self-construal is realized in interpersonal goals and interactional styles dominant within specific cultures (Lim 2016; Markus and Kitayama 1991; Tsai 2007). The key distinction proposed in the literature is between adjustment versus influence interpersonal goals, associated with predominantly collectivist (interdependent) and individualistic (independent) societies, respectively (Markus and Kitayama 2003). Cultures high in collectivism tend to feel duty to in-group, whereas those high in 
individualism tend to value personal independence (Hofstede 1980; Oyserman et al. 2002). Adjustment versus influence distinguish the two types of cultural orientations in line with these characteristics. That is, adjustment goals - characteristic of more collectivist groups - imply an interactional style whereby individuals strive to be in harmony with their environment, are attuned to others, and often suspend action, which at the physiological level is associated with low behavioral activity, low arousal, and a congruent preference for LAP affective states. Influence goals, on the other hand - characteristic of more individualistic groups - imply a style whereby individuals aim to control their environment by acting on it and changing it, which is associated with high behavioral activity and high arousal and a congruent preference for HAP states (Tsai et al. 2007).

The Mlabri as a society does not represent a typically individualistic or collectivist worldview, but exhibits features characteristic of both cultural orientations (Pookajorn 1992; Trier 2008). As a recently settled hunter-gatherer group, the Mlabri organize themselves in ways that emphasize both cooperation and solidarity on the one hand, and individuality and autonomy on the other (cf. Endicott 2011; Gibson and Sillander 2011; Woodburn 1982). People see themselves primarily as being connected to the group - a Mlabri person is someone who shares, lives together with, and 'loves the fellow Mlabri' (mak to? mla?) (Nimonjiya 2015). Yet, the affiliation with the group is not necessarily fixed. Individuals can leave at any time and live on their own or join other groups if they wish to do so. Similarly, people are free to enter and leave marriages at will and are not expected to follow a single religious doctrine (Trier 2008). Thus, although bearing some resemblance to collectivist systems in being oriented towards the group, the Mlabri social system is not geared towards adjustment in the absolute sense (but rather only 'horizontal adjustment' which emphasizes cooperation; Triandis and Gelfand 1998).

The Mlabri social system is, however, clearly opposed to influence and competition - typical of individualism - favoring cooperation and equality instead. Egalitarian ethos is very strong among the Mlabri, who traditionally did not have political or religious leaders or any form of institutionalized authority (Bernatzik 1938; Pookajorn 1992; Trier 2008). Despite the recent introduction of government-appointed village heads, social relations are still largely structured by egalitarian norms. Thus, most of what is described as "influence goals" in the literature on ideal affect (cf. Tsai et al. 2007) - e.g., trying to exert influence or claim authority over other people - is frowned upon and avoided among the Mlabri.

This plays out in subtle ways in everyday interactions. For example, Mlabri people are careful not to criticize other Mlabri and, if disagreements arise, they typically avoid challenging other people's views, instead stressing the uncertain and dependent nature of the issue at hand. Common expressions used in this 
context include: Pi?วy 'I don't know' and kalam du məy 'it depends on them, it's their business', similar to the authority-disavowing statements reported in the literature (cf. Rudge 2019; Stasch 2008), and Poh kimen paluh 'I am not criticizing/ telling you off' frequently prefacing advice to avoid the perception of superiority. Even if the matter at hand is trivial, e.g., using different pronunciation variants of the same word, people typically refrain from endorsing their own option, often suggesting others might be right instead. In more serious matters, it seems equally common for Mlabri people to avoid voicing strong disagreements or passing judgments. For example, moral norms and taboos (e.g., marriage rules) are presented in relatively straightforward terms when discussed in the abstract, but instances of transgressions (e.g., kin marriage) by specific individuals are almost never directly condemned, following a non-judgmental approach to taboo breaking reported also among other egalitarian hunter-gatherers (cf. Rudge 2019).

The above attitudes and practices reflect the deeply held belief among the Mlabri that one should not claim authority and signal dominance over other people. The Mlabri social system is premised on trying to maintain social equality, which necessarily implies "attentiveness to the relevant others in the social context" (cf. Markus and Kitayama 1991: 225). On the affective level, orientation towards equality results in high regard for non-dominance, restraint, and calm and is of fundamental importance to shaping critical attitudes towards some higharousal emotions such as anger. These cultural values and their enactment in interaction provide the sociocultural background for the spatial metaphors of affect. The specific metaphorical mappings from spatial notions to affective states are thus meaningful reflections not just of the bodily correlates of affective states, but also deeper cultural ideas in the Mlabri society on what is desirable and what not for one's well-being.

It is important to acknowledge that other factors, not foregrounded in the psychological literature on ideal affect, could also contribute to shaping Mlabri people's affective preferences codified in the klol-based metaphors. These include the environment of the forest and especially the way the Mlabri perceive and interact with the forest. Although the interviews discussed in the previous section did not require people to talk about ideology or worldview, Mlabri people's discussions of emotional well-being inevitably led to revealing their deeper ethical and aesthetic orientations, which turned out to be strongly rooted in their sense of identity as egalitarian forest people. Despite their forced settlement in permanent villages in the late 90s, the Mlabri have a vivid relationship with their recent past as hunter-gatherers and still today identify as 'forest people' (mla? bri?) (Trier 2008; Nimonjiya 2013). Thus, like many other forest people around the world, they see the forest not only in practical terms as source of livelihood, but also as a reference point that shapes their emic notions of 'good' and 'beautiful' (cf. Rudge 2017), and 
by extension also what they find desirable for their well-being. The forest was evoked in the interviews in the context of positive evaluations of images of the natural environment such as grass, lake, rocks, etc. (ni bri? pr? 'it exists in the forest'), and was implicit in references to sensory notions considered 'good' or 'beautiful' by virtue of their connection to the forest (e.g., cool temperature, green color). Similar to other Southeast Asian forest-dwelling groups (e.g., Endicott 1979; Wnuk 2016), the Mlabri see the forest as a reliable source of coolness offering protection from disease and danger (whereas heat, by opposition, is considered a threat). And while it is not free of its own dangers, many Mlabri view the forest as a place where one can feel at ease. In his ethnography based on fieldwork in the 70s, Trier remarks on Mlabri people's habits of taking frequent rests and notes his initial surprise at seeing children "sit passively watching the forest for a long time" (2008: 55). Also today the forest is still regarded as a place of rest and refuge by the Mlabri. In Mlabri terms, the forest is their 'home' ( $g \varepsilon \eta)$, and a place where the Mlabri can truly "feel the pleasure" of being Mlabri (Nimonjiya 2015: 140). The forest - as a physical environment which itself is good and beautiful - is thus a firm foundation of indigenous ethics and aesthetics, and a physical context reflecting the Mlabri ideal affect focused on calm states.

The ethnographic background described here provide a context for Mlabri preferences and cultural ideas and help explain the distinct metaphorical patterns in Mlabri language. As demonstrated, the association of desirable states with high and undesirable with low position in space reflect Mlabri people's ideal affect centered on contentment and tranquility. The expressions klol jur, klol khun, and klol kJbs jur are therefore not accidental or idiosyncratic, but are congruent with the broader sociocultural and physical world of the Mlabri.

\section{Discussion}

The Mlabri data presented here reveal a previously unreported pattern in metaphorical language of affect, whereby low is linked with happy, and high with unhappy states. This finding goes against the proposal that HAPPY Is UP might be universal or near-universal (Kövecses 2008). As an oft-cited example of a primary metaphor (e.g., Grady 2007; Hutchinson and Louwerse 2013; Ortiz 2011), HAPPY IS UP is presumed to have a special status since primary metaphors have been proposed to arise directly from experience and be "natural or even inevitable consequences of recurring associations in daily life” (Grady 2007: 193-194). The Mlabri data challenge this idea, showing that an opposite mapping is also possible. The same spatial notions that are linked to happy and unhappy states in English are linked to opposite affective states in Mlabri. So, whereas in English my heart sank denotes an 
undesirable state, an equivalent expression in Mlabri klol (Pa) jur (heart (PF) go.down) refers to a desirable state.

The Mlabri data bring attention to the complex nature of affect (Russell 1980) and the fact that there is more than a single possible mapping from vertical spatial concepts to affective states. Much of the previous work stressed the role of valence in the embodied experience that gives rise to metaphorical mappings from space to affect (Casasanto and Bottini 2014; Crawford 2009), but Mlabri metaphors indicate these mappings also depend on arousal (cf. Kövecses 1991). Although both English and Mlabri speakers' ideal affect is centered on positive states, they are prototypically high-arousal positive states for English and low-arousal positive states for Mlabri speakers. The mismatch between the respective metaphors reflects this difference. And while ideal affect varies broadly across cultures with many cultural instantiations of this variation reported in the literature (e.g., in popular media, child-mother interaction, religion, etc.; for a review see Tsai 2007), the Mlabri data is the first to show it can also manifest in lexicalized metaphors.

The linguistic diversity exposed here raises further questions about the possible cognitive diversity in how people in different cultures understand affect in spatial terms. The preliminary co-speech gesture data from Mlabri suggest metaphoricity goes beyond the verbal level, with Mlabri speakers' gestures mirroring the mappings found in the lexicon. It is an open question whether this effect would also extend into other aspects of non-linguistic cognition such as attention and memory, as it has been shown for English (e.g. Crawford et al. 2006; Meier and Robinson 2004), or if other metaphors diverging from the linguistically attested ones would prevail (cf. Casasanto 2011; Casasanto and Bottini 2014).

The present finding also calls for further examination of spatial metaphors of affect and other abstract valenced concepts in a broad sample of diverse languages. Metaphors such as HAPPY IS UP and GOOD IS UP are commonly seen as ubiquitous, but across languages valenced concepts exhibit a variety of spatial mappings. For example, a survey of a small set of languages from Southeast Asia, reports examples in which the word for "heart" combined with "high" can have both positive (e.g., Jingpho: myit madar tsò 'have pure/noble principles') and negative meanings (e.g., Burmese: cit-kû-cit-ne mrấ 'conceited'), and the same is true of the combination of "heart" with "low" (e.g., Lahu: ni-ma nû-nè ve "patient, calm, humble; gentle’ vs. Thai: jai tàm 'base, vile’) (Matisoff 1986: 21-22).

The case of Mlabri spatial metaphors of affect extends the growing literature on diversity of metaphorical patterns across languages. Conceptual metaphor literature is dominated by accounts of metaphor from large languages spoken by industrialized societies, often in urban settings, including many Standard Average European (SAE) languages. Investigations in smaller communities with diverse lifestyles and social organizations often reveal that patterns which seem natural 
from the perspective of SAE languages may in fact be less pervasive than imagined. This has been shown for a variety of domains, including cognition, time, and emotion (Boroditsky and Gaby 2010; Evans and Wilkins 2000; Núñez and Sweetser 2006; O'Meara and Majid 2020; Speed et al. 2019). The variation observed here is also an important reminder that metaphors are not merely embodied, but also sociocultural (or using the terminology in Rohrer [2007], they are embodied in both the bodily substrate and experiential sense of the term). Labels such as "primitive" and "simple" used in the context of primary metaphors might mistakenly suggest there is an elemental nature to them, but - as has been repeatedly observed in the metaphor literature - human bodies are only "apparently objective entities" (Núñez and Sweetser 2006: 441) and cannot be decoupled from the sociocultural context in which bodily experience occurs (Ibarretxe-Antuñano 2013; Kövecses 2005; Kirmayer 1992; Winter and Matlock 2017; Zlatev et al. 2012).

\section{Conclusions}

While all humans share certain basic bodily experiences underlying conceptual metaphors of affect, different cultures draw on the available sensorimotor correlates of emotion in distinct ways. Hence, rather than there being a single way, there are multiple experientially-based solutions to grounding the abstract idea of happiness in spatial physical terms. Whether one of them becomes entrenched in language depends largely on the linguistic system as well as the community's preferences and preoccupations, themselves shaped by a further range of factors including local environments, identities, and deeper histories. The Mlabri case reveals a novel spatial pattern of affective metaphor centered on contentment and tranquility that reflects deeper cultural ideas on happiness and well-being in the Mlabri society. The present investigation illustrates how converging insights from across language, gesture, and culture can shed light on the metaphorical understanding of affect, feeding into our broader knowledge of the world's metaphorical diversity.

\section{Abbreviations}

$\begin{array}{ll}3 & \text { third person } \\ \text { COMP } & \text { complementizer } \\ \text { NEG } & \text { negative } \\ \text { P } & \text { politeness marker } \\ \text { PF } & \text { perfective } \\ \text { POSS } & \text { possessive } \\ \text { SG } & \text { singular }\end{array}$


Acknowledgements: We are grateful to the Mlabri community of Baan Huai Yuak for participation in research. We thank Shu Nimonjiya for discussions, and Alice Rudge, three anonymous reviewers, and editor of Cognitive Linguistics for critical comments on earlier versions of the manuscript.

Research funding: This work was funded by European Union's Horizon 2020 research and innovation program under the Marie Skłodowska-Curie grant agreement No. 800004 and JSPS KAKENHI Grant Number JP18K11796.

Data availability statement: The dataset generated in the image categorization task and analyzed during the current study is available in the UCL Research Data Repository, https://doi.org/10.5522/04/14021804.

\section{References}

Ahlner, Felix. 2010. Body part terms in Kammu. Mon-Khmer Studies 39. 29-60.

Barrett, Lisa Feldman. 2006. Solving the emotion paradox: Categorization and the experience of emotion. Personality and Social Psychology Review 10(1). 20-46.

Bätscher, Kevin. 2015. Mlabri. In Paul Sidwell \& Mathias Jenny (eds.), The handbook of Austroasiatic languages, 1003-1030. Leiden: Brill.

Bernatzik, Hugo Adolf. 1938. Die Geister der gelben Blätter. München: F. Bruckmann.

Boroditsky, Lera \& Alice Gaby. 2010. Remembrances of times East: Absolute spatial representations of time in an Australian aboriginal community. Psychological Science 21(11). $1635-1639$.

Boster, James S. 2005. Emotion categories across languages. In Henri Cohen \& Claire Lefebvre (eds.), Handbook of categorization in cognitive science, 187-222. Amsterdam: Elsevier.

Casasanto, Daniel. 2011. Different bodies, different minds: The body specificity of language and thought. Current Directions in Psychological Science 20(6). 378-383.

Casasanto, Daniel \& Roberto Bottini. 2014. Spatial language and abstract concepts. Wiley Interdisciplinary Reviews: Cognitive Science 5(2). 139-149.

Cienki, Alan \& Cornelia Müller. 2008. Metaphor, gesture, and thought. In Raymond W. GibbsJr. (ed.), The Cambridge handbook of metaphor and thought, 483-502. Cambridge: Cambridge University Press.

Crawford, L. Elizabeth. 2009. Conceptual metaphors of affect. Emotion Review 1(2). 129-139.

Crawford, L. Elizabeth, Skye M. Margolies, John T. Drake \& Meghan E. Murphy. 2006. Affect biases memory of location: Evidence for the spatial representation of affect. Cognition and Emotion 20(8). 1153-1169.

Egerod, Søren. 1982. An English-Mlabri basic vocabulary. Scandinavian Institute of Asian Studies Newsletter 16. 14-20.

Egerod, Søren \& Jørgen Rischel. 1987. A Mlabri-English vocabulary. Acta Orientalia 48. 35-88.

Endicott, Kirk M. 2011. Cooperative autonomy: Social solidarity among the Batek of Malaysia. In Thomas Gibson \& Kenneth Sillander (eds.), Anarchic solidarity: Autonomy, equality, and fellowship in Southeast Asia, 62-87. New Haven: Yale University Southeast Asia Studies.

Endicott, Kirk M. 1979. Batek negrito religion: The world-view and rituals of a hunting and gathering people of Peninsular Malaysia. Oxford: Clarendon Press. 
Evans, Nicholas \& David Wilkins. 2000. In the mind's ear: The semantic extensions of perception verbs in Australian languages. Language 76(3). 546-592.

Geertz, Clifford. 1975. The interpretation of cultures: Selected essays. London: Hutchinson.

Gibson, Thomas \& Kenneth Sillander (eds.). 2011. Anarchic solidarity: Autonomy, equality, and fellowship in Southeast Asia. New Haven: Yale University Southeast Asia Studies.

Grady, Joseph. 1997. Foundations of meaning: Primary metaphors and primary scenes. Berkeley: University of California PhD dissertation.

Grady, Joseph E. 2007. Metaphor. In Dirk Geeraerts \& Hubert Cuyckens (eds.), The Oxford handbook of cognitive linguistics (Oxford handbooks), 188-213. Oxford: Oxford University Press.

Hofstede, Geert H. 1980. Culture's consequences: International differences in work-related values (Cross cultural research and methodology series). Beverly Hills, Calif: Sage Publications.

Hutchinson, Sterling \& Max Louwerse. 2013. Language statistics and individual differences in processing primary metaphors. Cognitive Linguistics 24(4). 667-687.

Ibarretxe-Antuñano, Iraide. 2013. The relationship between conceptual metaphor and culture. Intercultural Pragmatics 10(2). 315-339.

Kaiser, Bonnie N., Emily E. Haroz, Brandon A. Kohrt, Paul A. Bolton, Judith K. Bass \& Devon E. Hinton. 2015. "Thinking too much": A systematic review of a common idiom of distress. Social Science \& Medicine 147. 170-183.

Kendon, Adam. 2004. Gesture: Visible action as utterance. Cambridge: Cambridge University Press.

Kirmayer, Laurence J. 1992. The body's insistence on meaning: Metaphor as presentation and representation in illness experience. Medical Anthropology Quarterly 6(4). 323-346.

Kitayama, Shinobu, Hazel Rose Markus \& Masaru Kurokawa. 2000. Culture, emotion, and wellbeing: Good feelings in Japan and the United States. Cognition \& Emotion 14(1). 93-124.

Kövecses, Zoltán. 1986. Metaphors of anger, pride and love. Amsterdam: Benjamins.

Kövecses, Zoltán. 1991. Happiness: A definitional effort. Metaphor and Symbol 6(1). 29-47.

Kövecses, Zoltán. 2000. The concept of anger: Universal or culture specific? Psychopathology 33(4). 159-170.

Kövecses, Zoltán. 2005. Metaphor in culture: Universality and variation. Cambridge: Cambridge University Press.

Kövecses, Zoltán. 2008. Universality and variation in the use of metaphor. In Nils-Lennart Johannesson \& David Minugh (eds.), Selected papers from the 2006 and 2007 Stockholm Metaphor Festivals, 51-74. Stockholm: Stockholm University.

Kurdi, Benedek, Shayn Lozano \& Mahzarin R. Banaji. 2017. Introducing the Open Affective Standardized Image Set (OASIS). Behavior Research Methods 49(2). 457-470.

Lakoff, George \& Mark Johnson. 1980. Metaphors we live by. Chicago: University of Chicago Press.

Lakoff, George \& Mark Johnson. 1999. Philosophy in the flesh: The embodied mind and its challenge to Western thought. New York: Basic Books.

Lim, Nangyeon. 2016. Cultural differences in emotion: Differences in emotional arousal level between the East and the West. Integrative Medicine Research 5(2). 105-109.

Lu, Luo \& Robin Gilmour. 2004. Culture and conceptions of happiness: Individual oriented and social oriented SWB. Journal of Happiness Studies 5(3). 269-291.

Lutz, Catherine. 1985. Ethnopsychology compared to what? Explaining behavior and consciousness among the Ifaluk. In Geoffrey M. White \& John Kirkpatrick (eds.), Person, self, and experience: Exploring Pacific ethnopsychologies, 35-79. Berkeley: University of California Press. 
Lutz, Catherine. 1988. Unnatural emotions: Everyday sentiments on a Micronesian atoll and their challenge to western theory. Chicago: University of Chicago Press.

Markus, Hazel Rose \& Shinobu Kitayama. 1991. Culture and the self: Implications for cognition, emotion, and motivation. Psychological Review 98(2). 224-253.

Markus, Hazel Rose \& Shinobu Kitayama. 2003. Models of agency: Sociocultural diversity in the construction of action. In Virginia Murphy-Berman \& John Berman (eds.), Cross-cultural differences in perspectives on the self, Vol. 49, 18-74. Lincoln: University of Nebraska Press.

Matisoff, James. 1986. Hearts and minds in South-East Asian languages and English: An essay in the comparative lexical semantics of psycho-collocations. Cahiers de Linguistique-Asie Orientale 15(1). 5-57.

McNeill, David. 1992. Hand and mind: What gestures reveal about thought. Chicago: University of Chicago Press.

Meier, Brian P. \& Michael D. Robinson. 2004. Why the sunny side is up: Associations between affect and vertical position. Psychological Science 15(4). 243-247.

Moore, Christopher G. 2013. Heart Talk: Say what you feel in Thai. Bangkok: Heaven Lake Press.

Müller, Cornelia. 2008. Metaphors dead and alive, sleeping and waking: A dynamic view. Chicago: University of Chicago Press.

Nimonjiya, Shu. 2013. From 'ghosts' to 'hill tribe' to Thai citizens: Towards a new history of the Mlabri in Northern Thailand. Aséanie 32. 155-176.

Nimonjiya, Shu. 2015. From interacting to accessing: On relationship between the Mlabri and the Forest. Journal of Social Research 38(1). 137-70.

Núñez, Rafael E. \& Eve Sweetser. 2006. With the future behind them: Convergent evidence from Aymara language and gesture in the crosslinguistic comparison of spatial construals of time. Cognitive Science 30(3). 401-450.

O'Meara, Carolyn \& Asifa Majid. 2020. Anger stinks in Seri: Olfactory metaphor in a lesserdescribed language. Cognitive Linguistics 31(3). 367-391.

Ortiz, María J. 2011. Primary metaphors and monomodal visual metaphors. Journal of Pragmatics (Postcolonial Pragmatics) 43(6). 1568-1580.

Oyserman, Daphna, Heather M. Coon \& Markus Kemmelmeier. 2002. Rethinking individualism and collectivism: Evaluation of theoretical assumptions and meta-analyses. Psychological Bulletin 128(1). 3-72.

Pookajorn, Surin. 1992. The Phi Tong Luang (Mlabri): A hunter gatherer group in Thailand. Bangkok: Odeon Store Printing House.

Radden, Günter. 2003. How metonymic are metaphors. In René Dirven \& Ralf Pörings (eds.), Metaphor and metonymy in comparison and contrast, 93-108. Berlin: Mouton de Gruyter.

Rischel, Jorgen. 1995. Minor Mlabri: Hunter-gatherer language of Northern Indochina. Copenhagen: Museum Tusculanum Press.

Rohrer, Tim. 2007. Embodiment and experientialism. In Dirk Geeraerts \& Hubert Cuyckens (eds.), The Oxford handbook of cognitive linguistics (Oxford handbooks), 25-47. Oxford: Oxford University Press.

Rosaldo, Michelle Zimbalist. 1980. Knowledge and passion: llongot notions of self and social life (Cambridge studies in cultural systems 4). Cambridge: Cambridge University Press.

Rudge, Alice. 2017. Sound and socio-aesthetics among the Batek hunter-gatherers of Pahang State. Malaysia. London: University College London PhD dissertation. 
Rudge, Alice. 2019. Laughing when you shouldn't. American Ethnologist 46(3). 290-301.

Russell, James A. 1980. A circumplex model of affect. Journal of Personality and Social Psychology 39(6). 1161-1178.

Russell, James A. 2003. Core affect and the psychological construction of emotion. Psychological Review 110(1). 145-172.

Russell, James A. \& Lisa Feldman Barrett. 1999. Core affect, prototypical emotional episodes, and other things called emotion: Dissecting the elephant. Journal of Personality and Social Psychology 76(5). 805-819.

Sharifian, Farzad, René Dirven, Yu Ning \& Susanne Niemeier. 2008. Culture, body, and language: Conceptualizations of internal body organs across cultures and languages. Berlin: Mouton de Gruyter. https://doi.org/10.1515/9783110199109.

Speed, Laura J., Carolyn O’Meara, Lila San Roque \& Asifa Majid (eds.). 2019. Perception metaphors (Converging Evidence in Language and Communication Research (CELCR) v. 19). Amsterdam: John Benjamins.

Stasch, Rupert. 2008. Knowing minds is a matter of authority: Political dimensions of opacity statements in Korowai moral psychology. Anthropological Quarterly 81(2). 443-453.

Sweetser, Eve. 2007. Looking at space to study mental spaces: Co-speech gesture as a crucial data source in cognitive linguistics. In Monica Gonzalez-Marquez (ed.), Methods in cognitive linguistics (Human cognitive processing v. 18), 201-224. Amsterdam: John Benjamins.

Tolaas, Jon. 1991. Notes on the origin of some spatialization metaphors. Metaphor and Symbol 6(3). 203-218.

Triandis, Harry C. \& Michele J. Gelfand. 1998. Converging measurement of horizontal and vertical individualism and collectivism. Journal of Personality and Social Psychology 74(1). 118-128.

Trier, Jesper. 2008. Invoking the spirits: Fieldwork on the material and spiritual life of the huntergatherers Mlabri in northern Thailand (Jutland Archaeological Society Publications v. 60). Højbjerg: Jutland Archaeological Society.

Tsai, Jeanne L. 2007. Ideal affect: Cultural causes and behavioral consequences. Perspectives on Psychological Science 2(3). 242-259.

Tsai, Jeanne L., Brian Knutson \& Helene H. Fung. 2006. Cultural variation in affect valuation. Journal of Personality and Social Psychology 90(2). 288-307.

Tsai, Jeanne L., Felicity F. Miao, Emma Seppala, Helene H. Fung \& Dannii Y. Yeung. 2007. Influence and adjustment goals: Sources of cultural differences in ideal affect. Journal of Personality and Social Psychology 92(6). 1102-1117.

Uchida, Yukiko \& Shinobu Kitayama. 2009. Happiness and unhappiness in east and west: Themes and variations. Emotion 9(4). 441-456.

Wierzbicka, Anna. 1999. Emotions across languages and cultures: Diversity and universals (Studies in emotion and social interaction). Cambridge: Cambridge University Press.

Wikan, Unni. 1992. Beyond the words: The power of resonance. American Ethnologist 19(3). 460-482.

Winter, Bodo \& Teenie Matlock. 2017. Primary metaphors are both cultural and embodied. In Beate Hampe (ed.), Metaphor: Embodied cognition and discourse, 99-115. New York: Cambridge University Press.

Wnuk, Ewelina. 2016. Semantic specificity of perception verbs in Maniq. Nijmegen: Radboud University PhD dissertation.

Woodburn, James. 1982. Egalitarian societies. Man 17(3). 431-451.

Yu, Ning. 1995. Metaphorical expressions of anger and happiness in English and Chinese. Metaphor and Symbolic Activity 10(2). 59-92. 
Yu, Ning. 2007. Heart and cognition in ancient Chinese philosophy. Journal of Cognition and Culture 7(1-2). 27-47.

Zlatev, Jordan, Johan Blomberg \& Ulf Magnusson. 2012. Metaphor and subjective experience: A study of motion-emotion metaphors in English, Swedish, Bulgarian, and Thai. In Ad Foolen, Ulrike Lüdtke, Timothy Racine \& Zlatev Jordan (eds.), Moving ourselves - moving others: Motion and emotion in intersubjectivity, consciousness, and language, 423-450.

Amsterdam: John Benjamins. 